\title{
Por que empresas eticamente orientadas?
}

\section{Robert Henry Srour}

- Doutor em Ciências Humanas (Sociologia) pela Universidade de São Paulo (USP)

- Professor dos MBA da FIA (Fundação Instituto de Administração) e da Fipecafi (Fundação Instituto de Pesquisas Contábeis, Atuariais e Financeiras) da Faculdade de Economia, Administração e Contabilidade (FEA-USP)

- Autor de vários livros, como Em busca do sucesso: inteligência ética faz bem às empresas, Ética empresarial: a gestão da reputação e Poder, cultura e ética nas organizações: o desafio das formas de gestão

- Entre os cargos já exercidos, foi presidente da Companhia Paulista de Obras e Serviços (CPOS; 1995-2002), presidente da Empresa Metropolitana de Transportes Urbanos de São Paulo (EMTU; 1988) e conselheiro do Conselho Estadual de Educação de São Paulo (1985-1988)

- Diretor-geral da RHS Serviços Científicos

-rhenry@uol.com.br 
Resumo

O artigo discute os fundamentos sociológicos da adoção, pelas empresas, das estratégias de responsabilidade social corporativa e de sustentabilidade empresarial. Mostra como essa postura não decorre de uma benemérita tomada de consciência cívica ou de um surto de bom-mocismo, mas resulta de pressões cidadãs bem definidas e historicamente lastreadas. Destaca o crescente risco que ameaça o capital de reputação das empresas e aponta para a metamorfose da propriedade privada dos bens intangíveis em propriedade comum.

PALAVRAS-CHAVE: ÉTICA EMPRESARIAL • RESPONSABILIDADE SOCIAL CORPORATIVA • SUSTENTABILIDADE EMPRE-

SARIAL • CAPITAL DE REPUTAÇÃO • PÚBLICOS DE INTERESSE • CAPITALISMO SOCIAL • SOCIEDADE DA INFORMAÇÃO

- BENS INTANGÍVEIS

Abstract

This article discusses the sociological bases for adoption, by companies, of corporate social responsibility and business sustainability strategies. It shows us that this attitude does not derive from meritorious civic conscientiousness or nice-guy actions, but results from well-defined and historically-based citizenship pressure. It also points out the growing risk that threatens the reputational capital of the companies and points to a metamorphosis of private property of the intangible assets in common property.

KEYWORDS: BUSINESS ETHICS • CORPORATE SOCIAL RESPONSIBILITY • BUSINESS SUSTAINABILITY • REPUTATIONAL

CAPITAL・STAKEHOLDERS • SOCIAL CAPITALISM • INFORMATION SOCIETY • INTANGIBLE ASSETS

\section{Resumem}

Se discuten los fundamentos sociológicos de la adopción, por parte de las empresas, de las estrategias de responsabilidad social corporativa y de sustentablidad empresarial. Se muestra que esta postura no se debe a una benemérita toma de conciencia cívica o a una explosión de benevolencia, sino que es el resultado de presiones ciudadanas bien definidas e históricamente afianzadas. Se destaca el creciente riesgo que amenaza el capital de reputación de las empresas y se apunta hacia la transformación de la propiedad privada de los bienes intangibles en una propiedad común.

PALABRAS CLAVE: ÉTICA EMPRESARIAL • RESPONSABILIDAD SOCIAL CORPORATIVA • SUSTENTABILIDAD EMPRESA-

RIAL • CAPITAL DE REPUTACIÓN • PÚBLICOS DE INTERÉS • CAPITALISMO SOCIAL • SOCIEDAD DE LA INFORMACIÓN • BIENES INTANGIBLES 
0 título do artigo interroga e a resposta exige uma contextualização. A lógica do sistema capitalista é a da maximização dos lucros, não por razões ideológicas, mas por uma questão de racionalidade. Afinal, os empreendedores correm riscos ao investir capital: quanto maior e mais rápido for o retorno de seu investimento, menor será o grau de exposição àqueles riscos. Não é isso que dita o bom senso?

O destino do investimento, contudo, impõe uma reflexão: os empreendedores procuram o lucro em todo tipo de atividade, num impulso que se quer neutro do ponto de vista ético; alguns o fazem, porém, não importa o quão predatória seja a atividade escolhida. No caso, confundem lucro com pilhagem e descambam para uma postura antiética em que os interesses gerais são menosprezados em benefício de poucos. Por isso mesmo, somente o exercício de fortíssimas pressões externas poderia compelir os interesses empresariais a satisfazer outras demandas que não as próprias. Foi o que se deu nos últimos três decênios.

De fato, as empresas estão sendo forçadas a assumir práticas de responsabilidade social corporativa e, por extensão, a trilhar os caminhos da sustentabilidade empresarial, no mais das vezes, a contragosto. Assim sendo, quem exerce tais pressões? A sociedade civil - definida como cidadania organizada e ativa, ou como conjunto de agentes articulados e mobilizados capazes de intervenção política.

Em outras palavras, a lógica orgânica do sistema capitalista foi temperada por uma lógica exógena - fruto da reflexão ética e obra do ativismo político. Esse notável ponto de inflexão contribuiu para moldar o capitalismo social. ${ }^{1}$ Foi responsável, notadamente, por inaugurar uma nova partilha dos excedentes econômicos. Com efeito, parte menor dos lucros vem sendo convertida em "ganhos sociais", beneficiando muitos públicos de interesse afora os acionistas. ${ }^{2}$

A aplicação derivada dos lucros vai ao encontro da satisfação do bem comum e não significa subversão do sistema. Por exemplo, ao investir em capacitação de sua força de trabalho, as empresas valorizam seu capital intelectual, aumentam substancialmente a produtividade, melhoram a eficiência ao reduzir erros e, ipso facto, incrementam a própria rentabilidade. Mais ainda: ao detectarem novas oportunidades de negócio, tais como as energias limpas e renováveis, as empresas contribuem para diminuir os efeitos estufa - a Natureza agradece! - sem deixar de lucrar.

Em face disso, qual é a base ética das pressões cidadãs? A produção de bens e serviços supõe custos que não se resumem aos dispêndios econômicos, porque implica

1 Ao ampliar fortemente a base social da apropriação dos lucros e ao multiplicar consideravelmente o número de investidores, o capitalismo social contrasta com o capitalismo excludente em que a apropriação se cinge a um grupo restrito de proprietários capitalistas. Os exemplos mais significativos do fenômeno são os fundos de pensão de muitas categorias ocupacionais e a miríade de pequenos investidores que detêm ações de grandes corporações. Ver do autor: Poder, cultura e ética nas organizações, pp. 70-83.

2 Os públicos de interesse são as partes interessadas que mantêm relações ou vínculos de diversos tipos com a organização (stakeholders). 
também custos ambientais e sociais. Ora, quem suporta tais custos, geralmente invisíveis?

Os custos ambientais dizem respeito ao uso de recursos naturais (matérias-primas, água, energia) e às externalidades negativas geradas pelas empresas (desperdício, poluição). Vale dizer, não são dádivas da natureza - a pegada ecológica que o diga! Por sua vez, os custos sociais dizem respeito à formação da força de trabalho, à utilização da infraestrutura material e ao "mínimo legal" assegurado pelo Estado. ${ }^{3}$ Em conseqüência, não são frutos do acaso, mas custeados pelos impostos pagos pelo conjunto da sociedade!

Eis o fundamento objetivo da abordagem ética que passou a valer: a compreensão de que as empresas não podem simplesmente "pegar carona" nos bens coletivos sem dar uma contrapartida. No final do século XX, a sociedade civil aprendeu a fazer "política pela ética", o que equivale a dizer que esgrimiu um formidável poder de dissuasão ao acionar diversos canais que ganharam musculatura e consistência: a mídia, plural e investigativa, detentora de uma força superlativa, tem a faculdade de afetar negativamente o capital de reputação das empresas, quando não a de arruiná-lo; ${ }^{4}$ as agências de defesa do consumidor e dos cidadãos, a exemplo do Procon e da Vigilância Sanitária, dispõem de um arsenal de procedimentos capaz de fustigar diversos tipos de transgressões e de desestimular a reincidência; os movimentos de boicote promovidos por clientes, eloqüentemente silenciosos e multifacetados, provocam consideráveis perdas financeiras aos empreendimentos, quando não sua falência; a Justiça, apesar de sua proverbial morosidade, está cada vez mais equipada para aplicar sanções e multas dissuasórias.

Ocorre que a conversão de clientes em cidadãos ativos não se processou por algum condão mágico, mas derivou do recente processo histórico cujos vetores-chave transfiguraram a contemporaneidade. Por ordem de grandeza: a Revolução Digital, que ainda oculta muitas de suas virtualidades, redesenhou o modo de vida das sociedades e as arquiteturas organizacionais; ${ }^{5}$ a constituição de uma economia competitiva, em que o capitalismo deixou de ser oligopolista, adquiriu feições sociais e expandiu suas fronteiras para os confins do planeta $;^{6}$ a conquista de regimes políticos liberais pro-

30 mínimo legal consiste basicamente em direitos de propriedade, liberdade de empreender, garantia de execução de contratos, aplicação de legislação criminal e prevenção de práticas anticoncorrenciais.

40 valor das marcas e os laços incessantemente cultivados com os públicos de interesse formam esse ativo intangível.

5 Traços relevantes são a automação eletrônica dos processos, as telecomunicações em tempo real, a tecnologia da informação que permeia equipamentos e dispositivos de uso corrente, a co-responsabilidade técnica entre gestores e trabalhadores na organização do trabalho, a formação de equipes multifuncionais operando em ilhas de trabalho, o uso intensivo do trabalho mental e dos recursos simbólicos, a qualificação dos profissionais pagos por mérito ou por resultados. Ver Op. cit., pp. 44-59.

6 A globalização econômica fez com que o mundo se tornasse plano, no sentido de que, em busca de preços competitivos, tudo pode ser produzido em toda parte. A saber, a produção ocorre em âmbito mundial em função de transportes rápidos e baratos, da migração intensiva dos fatores de produção cujos custos de mobilidade despencaram e das economias de escala obtidas. Em paralelo, as comunicações instantâneas levaram a um crescimento geométrico do fluxo dos ativos financeiros e os intercâmbios comerciais atingiram píncaros jamais vistos nos processos de internacionalização anteriores. 
porcionou à cidadania os direitos de expressão e de manifestação inexistentes em regimes ditatoriais, e, simultaneamente, conferiu eficácia aos canais de pressão; o resgate do poder de escolha dos clientes que, agora, podem debandar para os concorrentes quando insatisfeitos com a qualidade dos produtos, os preços ofertados ou a logística do atendimento.

Qual configuração resultou dessas significativas mutações? Uma sociedade da informação que se caracteriza por uma economia do conhecimento e pela primazia dos ativos intangíveis. Essa economia, movida a capital intelectual: ${ }^{7}$ promoveu uma generalizada aplicação da ciência e da tecnologia à produção e à administração, convertendo-as em fontes de geração de valor; deflagrou uma vertiginosa aceleração das inovações que catapultaram a competitividade internacional a patamares inéditos (faz-se mais, melhor e a custos menores); tornou a tecnologia da informação indissociável do cotidiano de bilhões de pessoas, tanto pelo uso de celulares e de computadores quanto pelo impacto avassalador da Internet - redes informatizadas, bancos de dados compartilhados, teletrabalho, comunidades de colaboração; facultou uma extraordinária convergência das mídias e potencializou exponencialmente o trabalho humano. ${ }^{8}$

Nesse sentido, é crucial observar que, até ontem, o espaço, o tempo e a massa eram estanques, vale dizer, a transposição do espaço exigia um tempo extenso e a massa era tangível. ${ }^{9}$ Estávamos em pleno reino dos recursos materiais, físicos. Agora, espaço, tempo e massa ficaram permeáveis, o que equivale a dizer que a conectividade transpõe o espaço, a velocidade encurta o tempo e a intangibilidade supera a massa. Tudo ficou instantâneo, porque o planeta está interconectado; assistimos aos acontecimentos em tempo real e nossas respostas podem ser imediatas. Estamos, pois, em pleno reino dos recursos imateriais, simbólicos.

Milhões de pessoas têm acesso simultaneamente aos bens imaginários sem que isso deprecie ou diminua seu valor. Podem ouvir a mesma estação de rádio ou assistir ao mesmo canal de televisão sem que isso impeça outros milhões de juntar-se concomitantemente a elas. Estabeleceu-se, assim, um inédito divisor de águas: os bens intangíveis tendem a se definir como bens públicos. ${ }^{10} \mathrm{Ou}$, dito de outra forma, a Revolução Digital torna cada vez mais intangível a propriedade e tende a transcender o caráter

70 capital intelectual abrange a escolaridade formal, o nível de informação, as habilidades técnicas dos funcionários, a competência gerencial, a área de P\&D e as patentes registradas.

8 Integração dos recursos da Internet, da televisão digital, da telefonia celular, das redes de banda larga, do computador e da informática num contexto de mobilidade e de interatividade.

9 Basta lembrar a lenta transmissão das notícias por meio do correio convencional ou a dificuldade de comunicação, hoje inimaginável, via telegrafia com fios ou via telefonia conectada a uma central manual operada por telefonistas.

100 bem público é não-rival, não-excludente e seu consumo é coletivo: sua apropriação por um agente não diminui a quantidade a ser consumida por outros; todos têm acesso aos seus benefícios; seu suprimento não pode ser negado a quem se recusa a pagar por ele, o que possibilita uma atitude free rider (pegar carona). Os bens privados, em contraposição, são rivais, excludentes e seu consumo é individual: sua apropriação impede automaticamente seu consumo por outros agentes. 
individual, pleno e alodial da propriedade capitalista. Por exemplo, quando músicas, vídeos, textos, fotos, gráficos, fórmulas são postos na Internet, à revelia e contra a vontade de seus proprietários, a expropriação de seus direitos autorais faz com que a propriedade se torne comum a todos. Nessa toada, como manter privados os bens intangíveis? Afinal, por serem simbólicos, esses bens são reprodutíveis com facilidade crescente e a custos ínfimos: podem ser copiados, plagiados, pirateados, falsificados, clonados, maquiados, adulterados, contrafeitos, pilhados, contrabandeados... Consagra-se a fraude e celebra-se o colapso da propriedade intelectual!

De fato, na sociedade da informação, a intangibilidade funciona de forma anarquicamente subversiva: comanda uma revolução pacífica sem alarde ou bandeiras, sem barricadas ou armas, e seu furor iconoclasta metamorfoseia os bens privados em bens públicos. Resultados? As relações capitalistas de propriedade vêm sendo solapadas insensivelmente; a perpetuidade do sistema tal qual conhecido nesses dois últimos séculos está posta em xeque; e a virtualidade de mais um tipo de propriedade comunitária ganha substância. ${ }^{11}$

A universalização dos acessos aos saberes e ao entretenimento levanta, é claro, agudos questionamentos éticos. ${ }^{12}$ Pois como ficam os investimentos em pesquisas, em inovações, em processos de produção, de divulgação e de comercialização? Quem irá bancá-los? Como não desestimular os empreendedores, os cientistas, os inventores, os pesquisadores, os inovadores, os intelectuais em geral se não tiverem o mínimo de garantia de que seus esforços e suas descobertas serão reconhecidos e recompensados? Vale dizer: ao mesmo tempo em que muitos ficam inebriados com o sonho de acessos ilimitados à produção simbólica de bens e serviços, como viabilizar projeto tão futurista em economias de mercado centradas no capital de risco?

Num pólo simétrico, reponta a evidência de que não se pode mais fazer negócio "como sempre se fez" (business as usual). E as razões são múltiplas: a própria sobrevivência do sistema capitalista vê-se questionada na sua essência pelas novas tecnologias digitais e os desdobramentos desse grave questionamento ainda aguardam fatos e estudos, ${ }^{13}$ em função da cobertura global e em tempo real da mídia, a visibilidade

110 acesso aos bens torna-se livre e gratuito sob a égide da pirataria, mas ocorre também de maneira lícita: pululam os exemplos dos aplicativos que podem ser baixados sem restrições, além do desfrute sem ônus - já vetusto - das emissões de rádio ou dos programas oferecidos pela televisão aberta, ambos sustentados financeiramente por publicidade paga.

12 Indústrias inteiras estão à beira da morte - escreve Alvin Toffler - e precisam enfrentar as novas tecnologias que ameaçam pôr fim às proteções tradicionais da propriedade intelectual - por exemplo, direitos autorais, patentes e marcas registradas -, na qual apóiam sua própria existência ("Jamais houve mudança tão radical", revista Época Negócios, edição 8, outubro de 2007).

13 Caso interessante é o da banda de rock inglesa Radiohead, que ganhou as manchetes ao lançar um disco pela Internet em outubro de 2007. Ela convidou seus fãs a baixar as músicas de graça ou a fazer uma contribuição cujo montante ficava a critério de cada qual $(40 \%$ dos fãs contribuíram em média com 6 dólares). Nessas circunstâncias, como 0 grupo se sustenta? Ele reinventou o formato do negócio ao ganhar dinheiro principalmente com shows. Em vez de ficar à mercê da pirataria endêmica que grassa ou de depender da venda de gravações, distribuindo produtos físicos por intermédio de gravadoras, 
das empresas tornou-se inevitável, com ou sem crises, e sua vulnerabilidade cresceu substancialmente, ${ }^{14}$ mil olhos vigiam os passos das empresas graças às novas tecnologias e estão prontos a flagrar quaisquer práticas inescrupulosas; ${ }^{15}$ as decisões empresariais produzem efeitos sobre os públicos de interesse que detêm capacidade de retaliar, pondo em risco o capital de reputação das empresas - esse ativo tão laboriosamente construído; a existência de mercados competitivos requer suporte crescente dos públicos de interesse, porque uma boa reputação reduz resistências, angaria apoios e incrementa ganhos.

Mas o que é reputação, esse conceito atribuído pelos públicos de interesse? É a percepção que eles desenvolvem ao longo do tempo - um bem imaginário. Quando a reputação é boa, traduz-se em admiração, confiança e respeito; quando ela é má, conduz para a desconfiança, a rejeição e o estigma. Percepção do quê? Das ações cometidas no passado e no presente, numa leitura submetida a interpretações concorrentes e a manipulações potenciais. E, nessa esteira, geram-se expectativas quanto às ações futuras que os agentes avaliados irão adotar.

O risco de reputação assume, assim, o caráter de astro-rei do gerenciamento dos riscos ou das vulnerabilidades que ameaçam as empresas. Daí a necessidade da reflexão ética. Se ela for científica e competente, pode tornar-se fiadora da preservação e do fortalecimento do capital de reputação, na medida em que somente uma empresa eticamente orientada reúne as condições indispensáveis para angariar prestígio e assumir o estatuto de "empresa cidadã". E os pilares desse salto qualitativo são dois: a responsabilidade social corporativa e a sustentabilidade empresarial.

Responsabilidade social corporativa significa, em síntese, que as empresas se comprometem e se empenham em assegurar a qualidade de vida de seus públicos de interesses. Implica governança corporativa, parceria com os públicos de interesse e gerenciamento dos riscos ambientais. ${ }^{16}$

Por sua vez, a sustentabilidade empresarial corresponde ao fato de as empresas serem socialmente responsáveis (donde a abrangência maior do conceito de sustentabilidade), agirem de forma conseqüente em vista da própria perpetuidade e, não só pre-

viabilizou-se economicamente ao doar suas criações musicais! ("A economia do grátis", revista Exame, 31 de dezembro de 2007.)

14 Na era do Google, todo mundo pode tornar-se uma celebridade: quem for acusado de falcatrua na Internet, com ou sem razão, defronta-se com uma mancha praticamente impossível de apagar.

15 Os grampos telefônicos e os aparelhos miniaturizados que acoplam câmera fotográfica, filmadora e gravadora de som banalizaram a espionagem.

16 A governança corporativa é o sistema pelo qual as empresas são dirigidas e monitoradas: envolve as relações entre acionistas, Conselho de Administração, Diretoria, auditoria independente e Conselho Fiscal; estabelece um sistema de controles e incentivos orientado pelos interesses dos acionistas; confere transparência pública aos atos de gestão e protege a empresa contra eventuais abusos de poder; garante aos stakeholders, em última análise, tratamento mais equânime de seus interesses; torna mais fácil e a um custo menor 0 acesso aos investimentos externos. 
servarem o meio ambiente, mas restaurarem os sítios afetados por elas. Em outros termos, a sustentabilidade supõe que as empresas sejam viáveis economicamente, justas socialmente e corretas ecologicamente. Esse tríplice resultado (triple bottom line) contribui, em última instância, para assegurar a habitabilidade do planeta.

Do ponto de vista econômico, a sustentabilidade diz respeito, especificamente, a buscar o lucro responsável, gerar empregos, pagar imposto, inovar em produtos e processos, praticar a governança corporativa. Na esfera "social" significa respeitar direitos trabalhistas e humanos, repelir preconceitos e discriminações, promover o desenvolvimento social. No âmbito ecológico remete, no essencial, a reduzir insumos e resíduos, gerir os riscos ambientais com competência, praticar o consumo consciente em gastos e aquisições, e restaurar o meio ambiente.

Donde a seguinte conclusão: as empresas eticamente orientadas são as que geram lucro para os acionistas, protegem o meio ambiente e melhoram a vida de seus públicos de interesse, ao mesmo tempo em que resolvem problemas de caráter geral. Assim, ao levarem a sério esses compromissos e ao realizarem a façanha de traduzi-los em práticas, as empresas se credenciam para alcançar perenidade e boa reputação.

Para tarefas tão hercúleas, no entanto, é preciso mobilizar uma bateria de intervenções organizacionais: a gestão do conhecimento; a adoção de padrões internacionais de responsabilidade socioambiental; a criação de um ambiente propício às inovações (P\&D); o gerenciamento dos riscos incorridos; a integração das áreas de Comunicação Empresarial, Relações Públicas, Marketing e Publicidade e Propaganda. ${ }^{17}$ Tudo à luz da inteligência ética. ${ }^{18}$ Com qual propósito? Preservar o negócio contra as intempéries incessantes e contra uma concorrência cada vez mais inovadora e implacável. Eis uma agenda e tanto!

Resumo da ópera: sob pena de sofrer retaliações por parte de seus públicos de interesse, as empresas insertas num ambiente competitivo evitam agir como empreendimentos mercenários. Afinal, sua reputação influencia o volume das vendas e a qualidade delas, a compra de produtos e seus preços, a contratação de serviços, a obtenção de investimentos, os empregos que as pessoas procuram e os talentos a serem retidos. E por que isso? Porque os públicos de interesse costumam fazer apreciações que são vitais para a perenidade do negócio. Indagam, por exemplo, se a empresa seria um bom lugar para trabalhar (funcionários), uma boa provedora de produtos e serviços (clientes), uma boa compradora (fornecedores), uma boa parceira (comunidades locais) e um bom investimento (investidores).

17 Tal integração corresponde à instituição de um cargo estratégico, exige que a alta direção aja como unidade de ação e decisão, e objetiva cuidar da reputação ao gerir as percepções e as expectativas dos públicos de interesse.

18 A inteligência ética consiste em rastrear os fenômenos morais, dispor de diretrizes éticas consensuais, traduzir as diretrizes em práticas reais, estabelecer mecanismos de controle interno, analisar os eventuais desvios e suas implicações, bem como em corrigir as práticas em curso. 
Em conclusão, as empresas não competem apenas pelo mercado, mas para conquistar uma boa reputação: querem dispor de uma reserva de credibilidade que lhes confira a "licença para operar" e, por conseguinte, o benefício da dúvida em situação de crise. Procuram obter, sobretudo, um crédito de confiança que lhes outorgue uma vantagem competitiva para incrementar sua rentabilidade. Não o fazem por um surto de bom-mocismo.

Nesse contexto, a clara compreensão das implicações éticas das decisões a serem tomadas e das ações a serem praticadas corresponde a uma prudente sintonia com as mais recentes demandas do mercado.

\section{Referências}

FOMBRUN, Charles J. Reputation: realizing value from the corporate image. Boston: Harvard Business Scholl Press, 1996. NEEF, Dale. Managing corporate reputation and risk. USA: Elsevier, 2003.

SROUR, Robert Henry. Ética empresarial: a gestão da reputação. $2^{2}$ edição revista e atualizada. Rio de Janeiro: Campus/Elsevier, 2003.

Poder, cultura e ética nas organizações: o desafio das formas de gestão. $2^{\mathrm{a}}$ edição revista e atualizada. Rio de Janeiro: Campus/Elsevier, 2005. 